\title{
Displacements of an Active Moderately Rapid Landslide-A Dataset Retrieved by Continuous GNSS Arrays
}

\author{
Marco Mulas ${ }^{1, *(\mathbb{D})}$, Giuseppe Ciccarese ${ }^{1}$, Giovanni Truffelli ${ }^{2}$ and Alessandro Corsini ${ }^{1}$ (D) \\ 1 Department of Chemical and Geological Sciences, University of Modena and Reggio Emilia, via Giuseppe \\ Campi 103, 41125 Modena, Italy; giuseppe.ciccarese@unimore.it (G.C.); alessandro.corsini@unimore.it (A.C.) \\ 2 Emilia-Romagna Region-Regional Agency for Civil Protection and Territorial Security, Strada Giuseppe \\ Garibaldi 75, 43121 Parma, Italy; giovanni.truffelli@regione.emilia-romagna.it \\ * Correspondence: marco.mulas@unimore.it
}

Received: 6 July 2020; Accepted: 5 August 2020; Published: 8 August 2020

\begin{abstract}
This paper describes a dataset of continuous GNSS positioning solutions referring to slope movements in the $\mathrm{Ca}^{\prime}$ Lita landslide (Northern Apennines, Italy). The dataset covers the period from 24 March 2016 to 17 July 2019 and includes time-series of the daily position of three GNSS rovers located in different parts of the landslide: head zone, upper track zone, and lower track zone. Two different types of continuous GNSS arrays have been used: one is based on high-end Leica geodetic receivers, and the other is based on low-cost effective Emlid receivers. Displacements captured in the dataset are up to more than a hundred meters and are characterized by prolonged phases of slow movement and moderately rapid acceleration phases. The data presented in this contribution were used to underline slope processes and validate displacements retrieved by the application of digital image correlation to a stack of a satellite images.
\end{abstract}

Dataset: : Published as a supplement to this paper in the journal Data.

\section{Dataset License: : CC-BY}

Keywords: global navigation satellite systems (GNSS); precise point processing; real-time kinematic; monitoring; landslides; northern Apennines

\section{Summary}

This paper describes a dataset of continuous GNSS positioning solutions referring to slope movements in the $\mathrm{Ca}^{\prime}$ Lita landslide (Northern Apennines, Italy). The dataset covers the period from 24 March 2016 to 15 July 2019 and includes time-series of the daily position of three GNSS rovers located in different parts of the landslide: head zone, upper track zone, and lower track zone. During this time interval, the landslide experienced periods of slow movements and rapid accelerations that led to cumulated displacements in the order of hundreds of meters in the most active zone. The landslide is a roto-translational rock slide evolving in an earthslide - earthflow, for a total longitudinal length of approximately $3 \mathrm{~km}$ [1] and a maximum width of about $1.4 \mathrm{~km}$ (Figure 1). Since 2004, reactivations of the Ca' Lita landslide have been monitored with a broad spectrum of in situ and remote sensing technologies, leading to the identification of slow background movements alternated by paroxysmal reactivation phases characterized by moderately rapid movements in the order of several meters per day [1-3]. After the completion in 2011 of extensive remediation works to stabilize the landslide [2], its activity was reduced until March 2016, when another paroxysmal reactivation took place. 


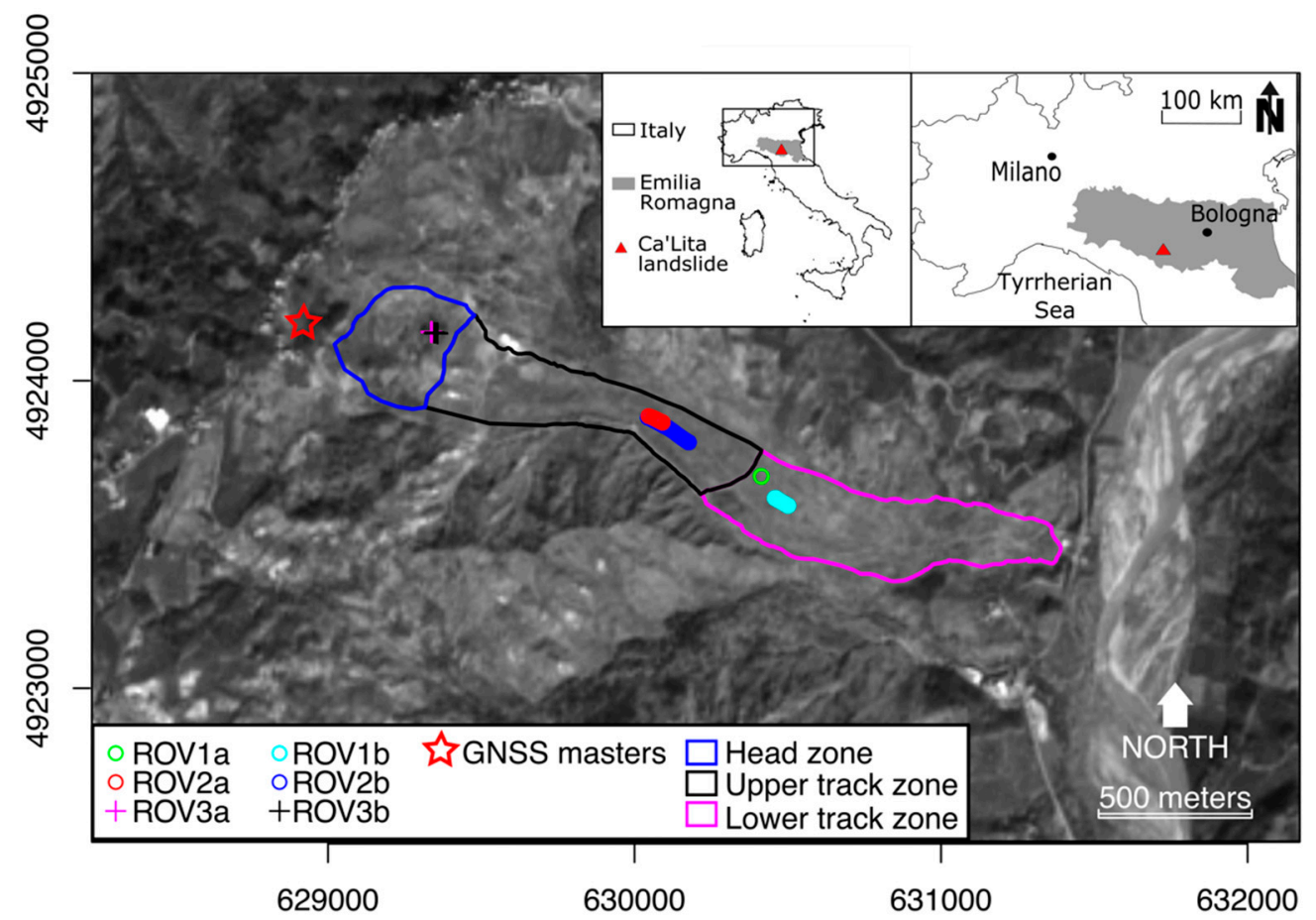

Figure 1. Geographical setting of the Ca' Lita landslide and the location of GNSS stations. Base map: Sentinel-2 (Band 4). Grid coordinates: WGS84/UTM32N (EPSG: 32632). ROV, rover.

After the 2016 reactivation, a continuous GNSS monitoring system was operated from 24 March 2016 to 01 June 2016 (Period "a") and then from 28 November 2016 to 15 July 2019 (Period " $b$ "). During Period " $a$ ", the GNSS array was deployed for risk emergency management, and it was set up using Leica devices: a double frequency "GMX902" receiver as the master unit and three single frequency "GMX901" receivers as rovers (ROV1 $a, R_{a} 2_{a}, R_{0 V}$ ) [4]. During Period " $b$ ", the Leica array, reduced to two rovers $\left(\mathrm{ROV}_{\mathrm{b}}, \mathrm{ROV} 2_{\mathrm{b}}\right)$, was complemented with a low-cost GNSS array based on Emlid single frequency receivers (Model Reach RS), one acting as master and the other as the rover $\left(\mathrm{ROV}_{\mathrm{b}}\right)$. During both periods, the GNSS master stations were re-installed in exactly the same position (materialized with a grouted pile that was left in-site), and the GNSS rovers were re-installed in the same geomorphic area using screw-drive piles.

Sharing this long-term dataset of slope movements in different geomorphic zones of an active complex landslide could be of benefit for those dealing with the study of the reactivation mechanisms of active landslides [5] and for those dealing with new remote sensing applications that require the ground truth to be compared [6-8]. As a matter of fact, the positioning solution time-series retrieved by this monitoring system have been recently used by the authors [9] to underline slope processes and to validate displacements retrieved by the application of digital image correlation (DIC) to a three year long stack of Sentinel-2 satellite images.

The GNSS data collection in the Ca' Lita landslide is still progressing, being founded by the Agency for Civil Protection and Territorial Security of Emilia-Romagna Region in the framework of the project "Prosecuzione dello studio e del monitoraggio frane Sassi Neri (Farini), in continuo e Pergalla (Bettola) in periodico" (SMART C.I.G.-SIMOG Z5C29E7E0C), Activity 4: "Landslide Monitoring with in-situ Permanent GNSS arrays".

\section{Data Description}

The dataset is composed of two tables in the comma separated files (CSV) format, namely "01_dataset_A.csv" and "02_dataset_B.csv" referring to the two intervals "a" and " $b$ " 
previously described (Supplementary Materials). Tables, delimited by "," and using "." as the decimal, are composed of five columns:

1. "Date" formatted as "YYYY-MM-DD" containing the daily date value;

2. "East" containing the east geographic component;

3. "North" containing the north geographic component;

4. " $\mathrm{H}$ " containing the ellipsoidal height (WGS84);

5. "Site" containing the name of the rover.

All coordinates are expressed in the WGS84/UTM32N (EPSG: 32632) spatial reference system.

\section{Methods}

The characteristics of the devices, processing, and positioning solutions obtained by the Leica GNSS array during monitoring Periods " $a$ " and " $b$ " (Figure 2) were presented in the paper by Corsini et al. [5]. This section presents the components and the workflow for positioning solutions using the Emlid GNSS low-cost array deployed during monitoring Period " $b$ ". The array is composed by two single frequency receivers, Model "Reach RS", which are based on a single-board computer with an embedded operating system including modules of the RTKLIB Open Source Program Package [10] for GNSS positioning and communication. The master station is capable of sending, using long range radio (LoRa), the real-time kinematic (RTK) corrections that are used by rovers to compute positioning solutions with different sampling frequencies. For this application, a $5 \mathrm{~Hz}$ frequency was used. The GNSS receivers operated as rovers, memorizing the RTK positioning solutions in $1 \mathrm{~h}$ long data packages that were sent, using a local Wi-Fi network, to the master node where a UMTS router, running an OpenVPN client, pushes hourly solutions to a remote server for data storage (Figure 3). Lastly, positioning time-series for each rover in both periods (i.e., ROV1 $1_{a, b}, R O V 2_{a, b}, R O V 3_{a, b}$ ) have been aggregated into daily time-series ( Figure 4; Figure 5) of daily median coordinate values. This was performed since the GNSS dataset was prepared in order to validate daily displacements retrieved by the DIC elaboration of satellite images.

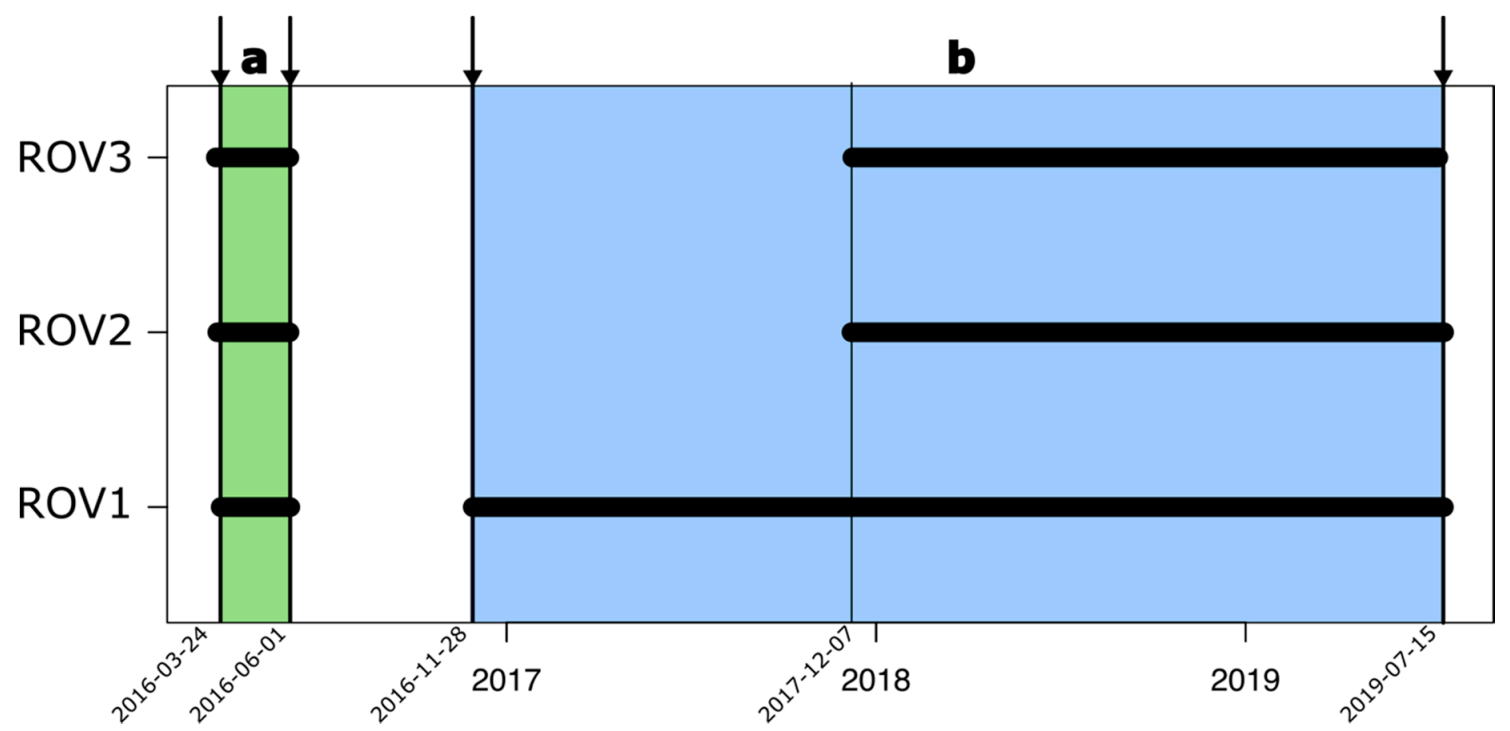

Figure 2. Time intervals covered by the GNSS positioning solution dataset. 


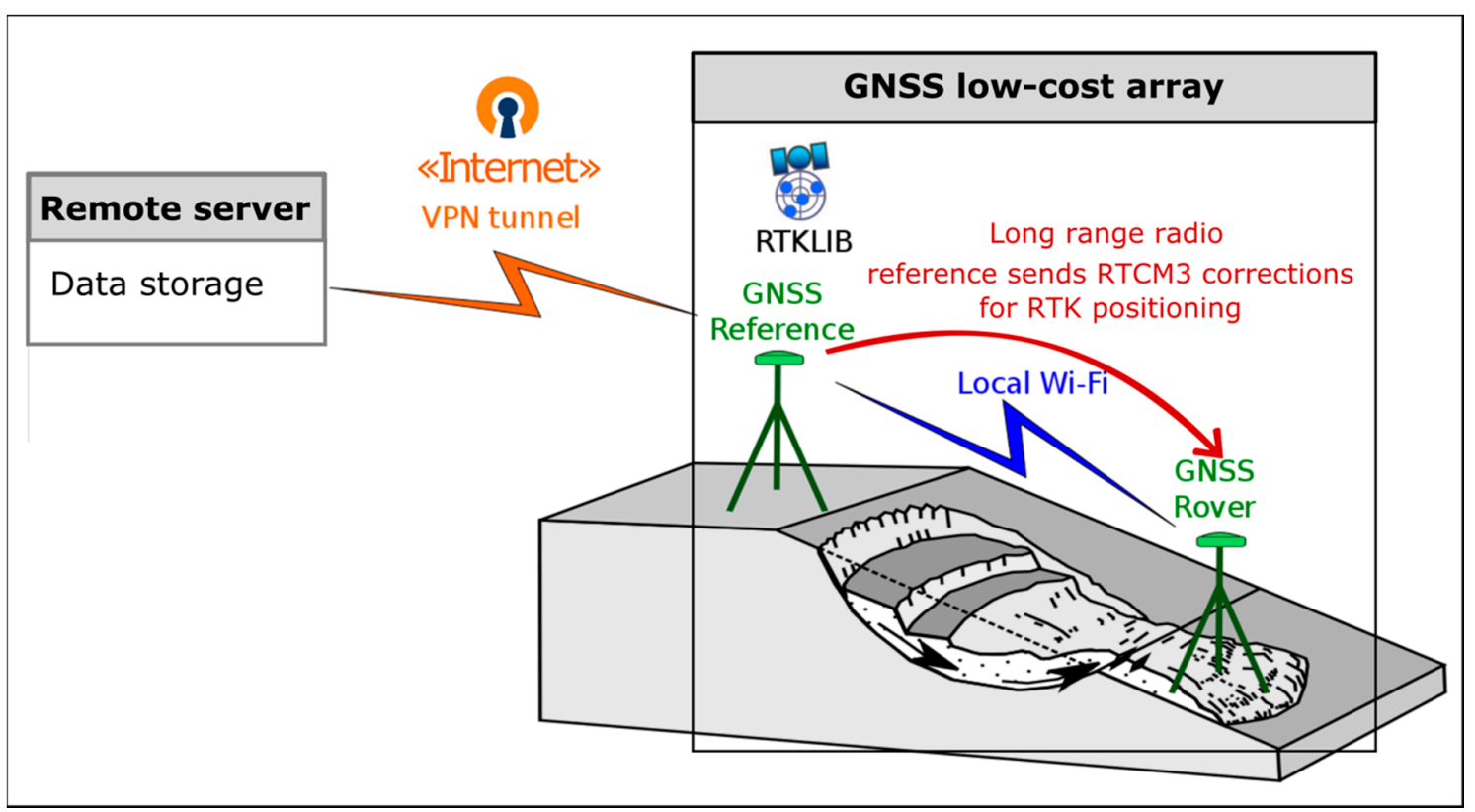

Figure 3. Workflow for GNSS positioning solution retrieval.
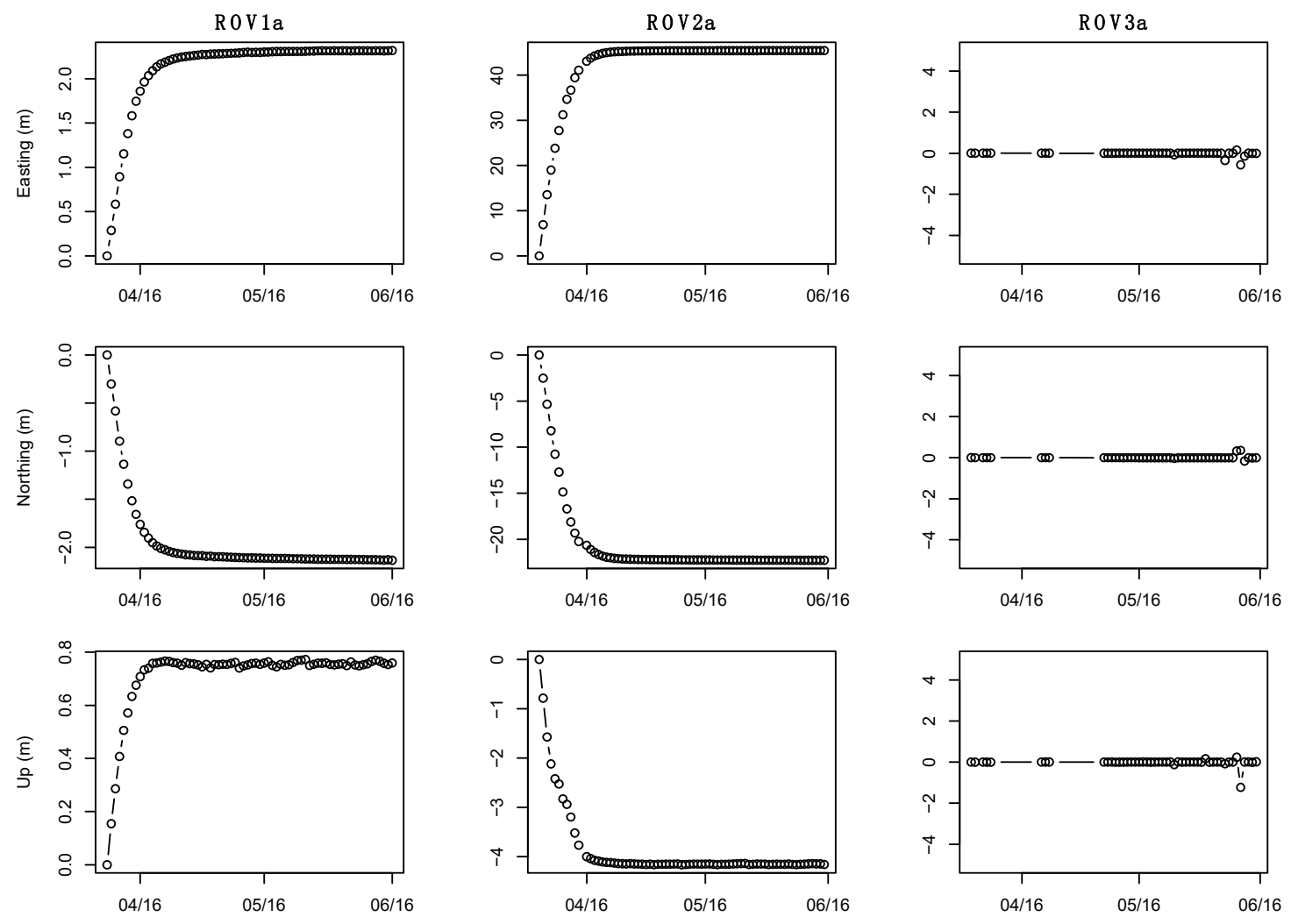

Figure 4. Displacement time-series of Period "a". 

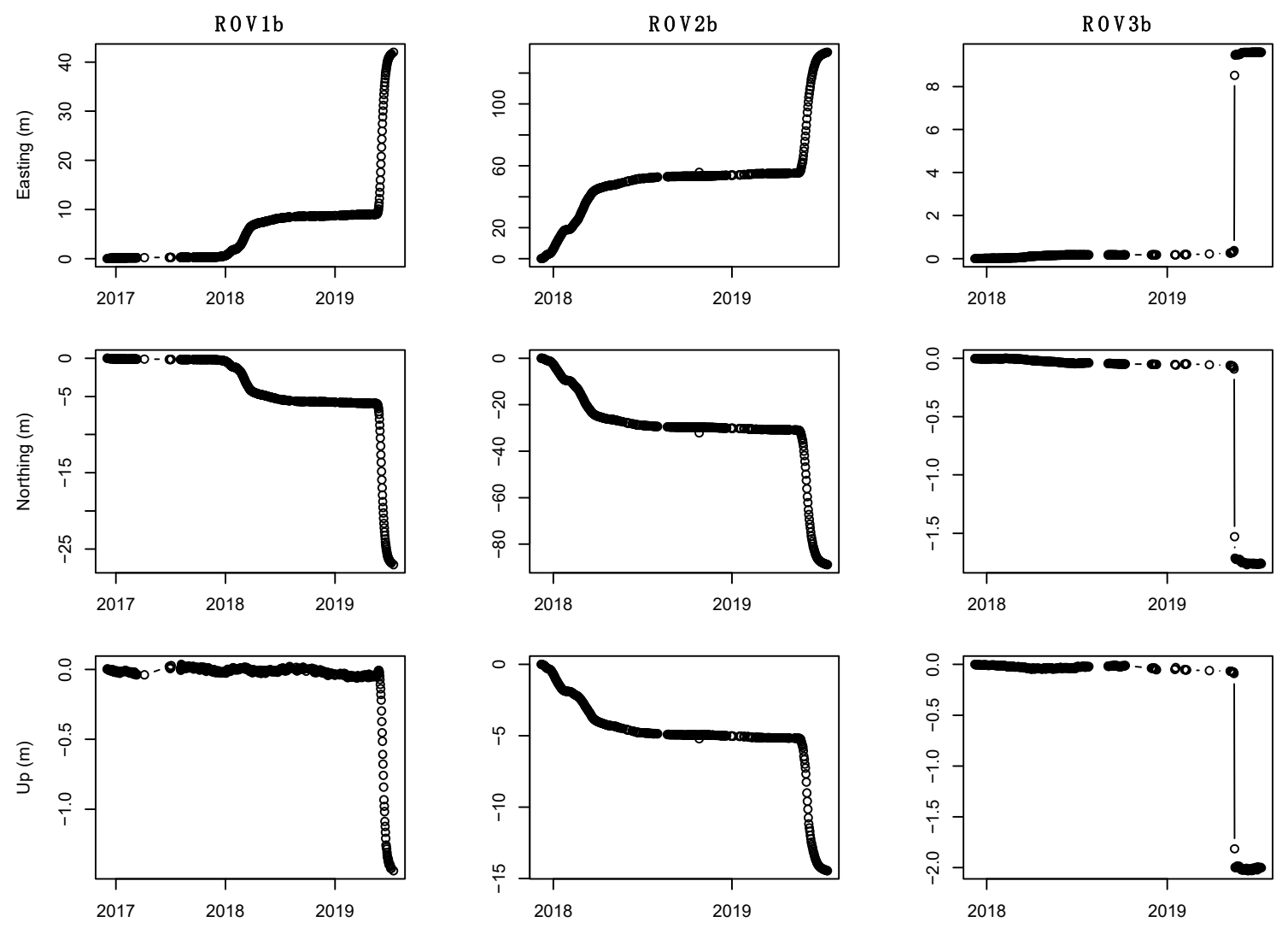

Figure 5. Displacement time-series of Period " $b$ ".

Supplementary Materials: The supplementary materials are available online at http://www.mdpi.com/2306-5729/ 5/3/71/s1.

Author Contributions: A.C. and M.M. conceived of and designed the experiments; all the co-authors (A.C., M.M., G.C. and G.T.) maintained the in situ monitoring system; M.M. analyzed the data; A.C. supervised the project; M.M. wrote the paper draft; all the co-authors revised the manuscript. All authors have read and agreed to the published version of the manuscript.

Funding: This work was supported by the Agency for Civil Protection and Territorial Security of Emilia-Romagna Region, under the framework of the project "Prosecuzione dello studio e del monitoraggio frane Sassi Neri (Farini), in continuo e Pergalla (Bettola) in periodico" (SMART C.I.G.-SIMOG Z5C29E7E0C), Activity 4: "Landslide Monitoring with in-situ Permanent GNSS arrays" referring to the permanent monitoring in other sites of interest to the Agency. Principal Investigators: A. Corsini, M. Mulas, and G. Ciccarese.

Conflicts of Interest: The authors declare no conflict of interest.

\section{References}

1. Borgatti, L.; Corsini, A.; Barbieri, M.; Sartini, G.; Truffelli, G.; Caputo, G.; Puglisi, C. Large reactivated landslides in weak rock masses: A case study from the Northern Apennines (Italy). Landslides 2006, 3, 115-124. [CrossRef]

2. Corsini, A.; Borgatti, L.; Caputo, G.; De Simone, N.; Sartini, G.; Truffelli, G. Investigation and monitoring in support of the structural mitigation of large slow moving landslides: An example from Ca'Lita (Northern Apennines, Reggio Emilia, Italy). Nat. Hazard Earth Sci. 2006, 55-61. [CrossRef]

3. Borgatti, L.; Corsini, A.; Marcato, G.; Ronchetti, F.; Zabuski, L. Appraise the structural mitigation of landslide risk via numerical modelling: A case study from the northern Apennines (Italy). Georisk Assess. Manag. Risk Eng. Syst. Geohazards 2008, 2, 141-160. [CrossRef]

4. Corsini, A.; Bonacini, F.; Mulas, M.; Ronchetti, F.; Monni, A.; Pignone, S.; Primerano, S.; Bertolini, G.; Caputo, G.; Truffelli, G.; et al. A portable continuous GPS array used as rapid deployment monitoring system during landslide emergencies in Emilia Romagna. Rend. Online Soc. Geol. Ital. 2015, 35, 89-91. [CrossRef] 
5. Mulas, M.; Ciccarese, G.; Ronchetti, F.; Truffelli, G.; Corsini, A. Slope dynamics and streambed uplift during the Pergalla landslide reactivation in March 2016 and discussion of concurrent causes (Northern Apennines, Italy). Landslides 2018, 15, 1881-1887. [CrossRef]

6. Mulas, M.; Corsini, A.; Cuozzo, G.; Callegari, M.; Thiebes, B.; Mair, V. Quantitative monitoring of surface movements on active landslides by multi-temporal, high-resolution X-Band SAR amplitude information: Preliminary results. In Proceedings of the Landslides and Engineered Slopes. Experience, Theory and Practice, Napoly, Italy, 12-19 July 2016; Volume 3, pp. 1511-1516.

7. Schlögel, R.; Thiebes, B.; Mulas, M.; Cuozzo, G.; Notarnicola, C.; Schneiderbauer, S.; Crespi, M.; Mazzoni, A.; Mair, V.; Corsini, A. Multi-Temporal X-Band Radar Interferometry Using Corner Reflectors: Application and Validation at the Corvara Landslide (Dolomites, Italy). Remote Sens. 2017, 9, 739. [CrossRef]

8. Iasio, C.; Novali, F.; Corsini, A.; Mulas, M.; Branzanti, M.; Benedetti, E.; Giannico, C.; Tamburini, A.; Mair, V. COSMO SkyMed high frequency-High resolution monitoring of an alpine slow landslide, corvara in Badia, Northern Italy. In Proceedings of the 2012 IEEE International Geoscience and Remote Sensing Symposium, Munich, Germany, 22-27 July 2012; pp. 7577-7580.

9. Mulas, M.; Giuseppe, C.; Truffelli, G.; Corsini, A. Integration of Digital Image Correlation of Sentinel-2 data and continuous GNSS for long-term slope movements monitoring in moderately rapid landslides. Remote Sens. 2020. under review.

10. Takasu, T.; Yasuda, A. Development of the low-cost RTK-GPS receiver with an open source program package RTKLIB. In Proceedings of the International Symposium GPS/GNSS, International Convention Center Jeju, Jeju Island, Korea, 4-6 November 2009.

(C) 2020 by the authors. Licensee MDPI, Basel, Switzerland. This article is an open access article distributed under the terms and conditions of the Creative Commons Attribution (CC BY) license (http://creativecommons.org/licenses/by/4.0/). 